\title{
Corte y cortesanos: evolución tipológica residencial y ecos del palacio del monarca en el Reino de Valencia entre los siglos XIII y XV
}

\author{
Federico IBORRA BERNAD \\ Departamento de Composición Arquitectónica \\ Universidad Politécnica de Valencia \\ feibber@cpa.upv.es
}

\section{RESUMEN}

Un palacio real no es más que una vivienda de grandes dimensiones. La imagen de prestigio y poder en las residencias aristocráticas vendrá vinculada, en gran medida, a la evocación del palacio del monarca. Éste, a su vez, recoge influencias externas y sus necesidades protocolarias irán aumentando con el tiempo. Nuestra aportación intentará rastrear la génesis y desarrollo de algunos modelos áulicos vigentes en el antiguo Reino de Valencia entre los siglos XIII y XV.

Palabras clave: palacio, gótico civil, Valencia.

\section{Court and courtiers: palatial development and influence from the royal palace in the kingdom of Valencia between $13^{\text {th }}$ and $14^{\text {th }}$ centuries}

\begin{abstract}
A royal palace is no more than a large house. The image of prestige and power in the aristocratic residences was related to the evocation of the monarch's palace. This, in turn, collects external influences, and ceremonial needs will be increased over time. Our contribution will attempt to trace the genesis and development of some aulic existing models in the former Kingdom of Valencia between the $13^{\text {th }}$ and $15^{\text {th }}$ centuries.
\end{abstract}

Key words: palace, civil gothic, Valencia. 


\section{Modelos románicos y andalusíes}

La arquitectura residencial medieval sigue siendo una asignatura pendiente para la historiografía. En el caso valenciano han sido varios los autores que han hablado del palacio gótico del siglo XV como un prototipo genérico e idealizado ${ }^{1}$. Existen otras publicaciones que recogen repertorios de edificios señoriales de diversas épocas, con abundante información gráfica y noticias históricas ${ }^{2}$. Finalmente, contamos con buenas monografías de casos singulares, algunas de ellas fruto de una paciente labor de archivo $^{3}$. Sin embargo, es todavía necesario un estudio tipológico más amplio, que no se quede en unos pocos ejemplos tardíos y que ofrezca una visión de conjunto, sobre el que este texto pretende abrir algunas líneas de reflexión.

Cuando se habla de la arquitectura residencial de los territorios de la Corona de Aragón suele pensarse en los palacios góticos construidos alrededor de un patio, caracterizado siempre por la presencia de una escalera exterior. La historiografía tradicional, basada en los estudios pioneros de Josep Puig i Cadafalch, ha entendido esta tipología como una herencia de las casas patio romanas, que habría pervivido en Cataluña durante siglos, expandiéndose tras las conquistas de los reinos de Mallorca, Valencia, Sicilia o Nápoles ${ }^{4}$. Sin embargo, este enfoque es erróneo. Estudios más recientes, como los de Eduard Riu-Barrera, ponen de manifiesto que los palacios barceloneses del siglo XIII eran mucho más modestos, consistiendo generalmente en un bloque único al fondo o en el flanco de una parcela totalmente libre, sobre la que sólo en época posterior se construyeron nuevas alas configurando el característico patio central. A este tipo pertenece claramente el núcleo antiguo del Palacio Arzobispal de

\footnotetext{
1 Estos análisis son una gran ayuda para introducirse en el tema, pero suelen pecar de centrar su visión en el prototipo de edificio tardío, estudiado con la ayuda de fuentes documentales o literarias de primera mano. En esta línea destacan aportaciones como: A. ZARAGOZÁ CATALÁN, "La casa senyorial valenciana", Palau de l'Almirall, Valencia, 1991, pp. 79-94; "Modos de vida. Siglos XIV-XVI”, T. SIMÓ TEROL y M. J. TEIXIDOR DE OTTO, La vivienda y la calle, la calle de Cavallers de Valencia, Valencia, 1996, pp. 182-199; y D. BENITO GOERLICH, "La casa del caballero", El hogar de los Borja, Valencia, 2001, pp. 73-90. Centrado en el tema de los patios: M. GÓMEZ-FERRER LOZANO, "Patios y escaleras de los palacios valencianos en el siglo XV", Historia de la Ciudad IV. Memoria urbana, Valencia, 2005, pp. 113-142.

2 Como por ejemplo, F. PÉREZ DE LOS COBOS GIRONÉS, Palacios y casas nobles de Valencia, Valencia, 1991. El mismo autor ha publicado posteriormente libros abarcando las tres provincias de la Comunidad Valenciana. Con fotografías más modestas pero aportando planos, F. MUÑOZ ANTONINO, Las casas señoriales de Murviedro, Valencia, 1999. Puede añadirse la Tesis Doctoral inédita de C. LÓPEZ GONZÁLEZ, Los palacios góticos de la ciudad de Valencia. Su estudio y catalogación. Ejemplo gráfico, Valencia, 1995.

3 Respecto a títulos monográficos: D. BENITO GOERLICH, "El Palau dels Almiralls d'Aragó", Palau de l'Almirall, Valencia, 1991, pp. 97-110; D. BENITO GOERLICH y A. SERRA DESFILIS, "El Palau de Les Corts, antiga casa dels Borja", Palau de Les Corts, Valencia, 1995, pp. 19-42; VV.AA., Palau dels Centelles d'Oliva, recull gràfic o documental, Oliva, 1997; L. ARCINIEGA GARCÍA, El Palau dels Borja a València, Valencia, 2003; y M. GÓMEZ-FERRER LOZANO y J. CORBALÁN DE CELIS DURÁN, "La casa del Obispo de Tortosa, Alfonso de Aragón. Un palacio valenciano en la encrucijada entre dos siglos (XV-XVI)", Ars Longa, 13 (2004), pp. 11-31.

4 Estas ideas fueron expuestas, por ejemplo, en J. PUIG I CADAFALCH, "La maison particulière", P. LAVEDAN (coord.), L'architecture gothique civile en Catalogne, Mataró, 1935, pp. 94-105.
} 
Barcelona (c. 1270), la parte primitiva de la casa de Berenguer de Aguilar (finales del s. XIII) o los restos de la casa de los Marc, en el denominado Pati de En Llimona ${ }^{5}$.

Aceptar esta realidad nos lleva a alejarnos de la idea tradicional de un modelo arquitectónico bien definido que los repobladores cristianos habrían trasladado tras la conquista de los reinos musulmanes o las campañas italianas. En realidad, la evolución tipológica tuvo lugar en la segunda mitad del siglo XIII, cuando los reinos de Valencia y Mallorca estaban ya anexionados a la Corona de Aragón. Es lógico entender, además, que muchas experimentaciones e innovaciones debieron llevarse a cabo en los territorios recién conquistados, donde se pretendía transformar a marchas forzadas un tejido urbano andalusí en una ciudad cristiana. Por otra parte, algunos elementos, como las escaleras exteriores de los patios, realmente provienen de Oriente y llegaron a España a finales del siglo XIII a través de Italia, lo que explica su ámbito de difusión centrado en los territorios ribereños y su escasa repercusión en las tierras interiores de la Corona de Aragón.

Evidentemente hubo una aportación cultural de los primeros repobladores cristianos de Mallorca y Valencia, pero debemos entenderla dentro de unos esquemas comunes a toda la Europa románica. Esta aportación es patente en la planificación de viviendas adosadas y, para los propietarios más pudientes, bloques de única crujía paralelos a la calle, con un gran espacio libre delante o detrás. En ámbito valenciano, podría responder a este último modelo el cuerpo de fachada de la casa de Joan de Valeriola, recientemente restaurada. Aunque el edificio se organiza en torno a un patio con ventanas del siglo XIV, se conserva en planta baja un enigmático arco cortado por sobrepasar el nivel del forjado que nos hace pensar en una escalera lineal adosada a la medianera, como la restituida en la reconstrucción hipotética de la casa barcelonesa de los Marc. La decoración de las techumbres de la casa de los Valeriola remite a los siglos XIV y XV, excepto la de la pieza principal, con un alfarje de cinta y saetino muy elaborado, que recuerda mucho a la cubierta de la iglesia de Santa María de Liria (c. 1270).

Sin embargo, hay que pensar que no siempre se reedificaba de nueva planta y que el aprovechamiento de las preexistencias andalusíes pudo llevar a soluciones nuevas. La destrucción no fue total y, en este sentido, cabe recordar el ejemplo de la antigua sala del Palacio de Pinohermoso en Játiva, que conservó incluso las yeserías y armadura de cubierta original hasta el siglo $\mathrm{XX}^{6}$. Podríamos, además, plantear una posible relación entre las casas hispanomusulmanas y las tipologías populares derivadas de la doble crujía, tanto en fachada como a fondo de patio, transmitidas hasta la actualidad en ámbito valenciano ${ }^{7}$. En esta línea, las excavaciones de la Alquería de

5 E. RIU-BARRERA, “Tipus i evolució de les cases urbanes”, E. RIU-BARRERA (coord.), L'Art gòtic a Catalunya. Arquitectura III. Dels palaus a les masies, Barcelona, 2003, pp. 146-151.

6 Estas piezas se encuentran actualmente en el Museo del Almudín, en la misma localidad. L. TORRES BALBÁS, “Játiva y los restos del palacio de Pinohermoso", Al-Andalus, XXIII (1958), pp. 143-171.

7 Algunos autores, como Miguel del Rey, atribuyen un origen renacentista a estos edificios populares de doble crujía (M. DEL REY AYNAT (coord.), Alqueries. Paisatges i arquitectura en l'horta, Valencia, 2002, pp. 145 y ss.) Este autor observó el predominio de la planta basilical en las alquerías claramente medievales del entorno de Valencia y supuso un cambio en el siglo XVI o, como mucho, a finales del XV. Sin embargo, existen ejemplos de palacios urbanos y casas señoriales de doble crujía fechables en los siglos XIII y XIV. Por 
Bofilla, abandonada en el siglo XIV, muestran abundantes ejemplos de vivienda rural de doble crujía al fondo de un patio ${ }^{8}$. En tejido urbano podemos encontrar edificios de doble crujía recayente a fachada desde el siglo XV, como alguno de los palacios de la calle Exarchs de Valencia o de la calle Tamarit en Oliva ${ }^{9}$. También la planta del palacio de Montortal en Játiva apunta a una doble crujía, quizá anterior, pues queda extrañamente combinada con un patio del siglo XIV desplazado a un lateral ${ }^{10}$.

Más estrecha es la relación entre algunos grandes palacios del siglo XIII y los modelos andalusíes puesto que, además de la doble crujía, se mantiene el esquema tripartito de sala flanqueada por alhanías y pórtico. El caso más evidente es el del núcleo primitivo del Real de Valencia (fig. 1) levantado por Jaime I posiblemente hacia 1250 , al trasladar su corte fuera de la ciudad ${ }^{11}$. Aunque estaba resuelto en cantería, su planta respondía al tipo descrito e incorporaba columnas de expolio y yeserías -las que se han hallado, ya posteriores- en un espacio porticado con una fuente en el centro, que se abría a un jardín con alberca, a nivel inferior ${ }^{12}$.

Probablemente este pabellón primitivo estaba concebido para recibir en planta baja, al igual que en la Aljafería de Zaragoza, o como hacía Alfonso X en Sevilla. Aún así, podemos imaginar la existencia desde el primer momento de estancias altas de uso privado, algo no ajeno a la tradición andalusí. Podría haber dos alhanías emergentes a modo de torrecillas y quizás una comunicación cubierta sobre el pórtico, algo más bajo que la sala posterior, lo que daría al edificio un aspecto exterior muy próximo al Palacio de Galiana en Toledo ${ }^{13}$. Se ha encontrado en Alhama de Murcia un soporte

otra parte, la casa popular valenciana y la alicantina desarrolla esquemas distributivos en $\mathrm{T}$ o $\mathrm{T}$ invertida, con dos alcobas, que recuerda en gran medida a modelos de ascendencia oriental.

8 Véase P. LÓPEZ ELUM, La alquería islámica en Valencia. Estudio arqueológico de Bofilla, siglos XI al XIV, Valencia, 1994.

9 Véase, respectivamente: C. LÓPEZ GONZÁLEZ, op. cit, 1995, pp. 400-402; y M. DEL REY AYNAT, Lugares. Una selección de textos, proyectos y obras en torno al tiempo y al lugar, Valencia, 2004, pp. 143-149.

10 El edificio es de propiedad particular y no hay bibliografía sobre el mismo, aunque la reciente restauración llevada a cabo por el arquitecto Vicente Torregrosa ha permitido descubrir diversos elementos primitivos antes ocultos. Los arcos apuntados del patio, que recuerdan a los del Palacio del Almirante en Valencia, son los que nos sirven para datarlo.

11 Para más detalles sobre las posibles fases de evolución del edificio primitivo: F. IBORRA BERNAD, "La imagen y la arquitectura del palacio del monarca en los reinos de Valencia y Mallorca durante el siglo XIII", Las Artes y la Arquitectura del Poder. Actas del XIX Congreso del CEHA, (en prensa). Aparte de la historiografía tradicional, una recopilación de textos recientes firmados por diversos especialistas, como M. Gómez-Ferrer, J. Bérchez, A. Serra o L. Arciniega, se publicó en: J.V. BOIRA MAIQUES (coord.), El Palacio Real de Valencia. Los planos de Manuel Cavallero (1802), Valencia, 2006. Cabe referir además la reciente y completa monografía: M. GÓMEZ-FERRER LOZANO, El Real de Valencia (1238-1810). Historia arquitectónica de un palacio desaparecido, Valencia, 2012.

12 En la década de 1980 se excavó el área del pórtico, hallándose columnas de mármol (algunas reutilizadas) formando un pórtico parecido al de la Aljafería de Zaragoza. Sobre estas excavaciones: V. ALGARRA et alii, "Las excavaciones arqueológicas en el Palacio Real", J.V. BOIRA MAIQUES (coord.), op. cit., 2006, pp. 3346. En cuanto a la cronología, la fábrica era de sillería con marcas de cantería, y las basas nuevas respondían a modelos cristianos de finales del XII o principios del XIII, como las presentes en San Vicente de Ávila, la cripta de Santiago de Compostela o la Catedral de Burgos, según C. BARCELÓ, P. CRESSIER y J.V. LERMA, "Bases et chapiteaux califaux inédits de Valence", Cuadernos de Madinat al-Zahrā, II (1988-90), pp. $29-54$.

13 F. CHUECA GOITIA, Historia de la arquitectura española. Edad Antigua y Edad Media [1964], Ávila, 2001, pp. 513-520. 
para pileta de abluciones del siglo XII o XIII que imita una estructura de este tipo, con torres gemelas emergentes que recuerdan a los miradores nazaríes ${ }^{14}$. También los restos del Alcázar Menor de Murcia, levantado de nueva planta a mediados del XIII, presentan dos torres flanqueando el pórtico, aunque mucho más gruesas ${ }^{15}$.

En la segunda mitad del siglo XIII va consolidándose la importancia de la planta superior dentro del protocolo de la corte. En el primitivo palacio episcopal de Valencia (c. 1260) vemos perfectamente definida esta tendencia (fig. 1). La gran sala ha reducido su altura y presenta ahora grandes arcos abiertos a un patio o jardín trasero, lo que delata ya un uso diferente. Existen en ella dos enigmáticos arcos transversales, demasiado separados para ayudar a soportar el forjado. Su función real sería sostener la estructura de la planta noble, concretamente una columna central para la sala y un muro cerrando la cámara privada, según una tipología que veremos más adelante. En su plano urbano, el padre Tosca marca claramente esta distinción con cuerpos de alturas diferentes. También nos muestra todavía el pórtico medieval de dos plantas -muy alterado- encuadrado entre sendas torres, de las cuales la más irregular parece ser preexistente ${ }^{16}$.

El mismo esquema, en versión más modesta, se repite en la antigua casa señorial del despoblado de Sinyent, junto a Poliñá del Júcar (fig. 1). Encontramos la misma planta baja tripartita de doble crujía, abierta con arcos en todos sus frentes. La crujía propiamente residencial apenas es un poco más ancha que el pórtico, aunque conserva los dos extraños arcos que aquí carecen de función, puesto que simples tabiques servían para segregar las habitaciones del piso superior ${ }^{17}$.

Por su parte, el núcleo antiguo del palacio del Real debió crecer un piso, llegando a tener un aspecto parecido al pabellón principal de la Almudaina de Palma ${ }^{18}$. Una

14 J. NAVARRO PALAZÓN y P. JIMÉNEZ CASTILLO, "Maquetas arquitectónicas en cerámica y su relación con la arquitectura andalusí”, Casas y palacios de Al-Andalus, Madrid-Barcelona, 1995, pp. 287 y ss. Los autores interpretan la plaza como la evocación de un patio con dos pabellones, cada uno con una torre. Sin embargo, debe tenerse en cuenta que el hueco central -interpretado como "patio"- iba cerrado con una tapadera. Además, considerándolo un pabellón único queda mucho más proporcionado.

15 J. NAVARRO PALAZÓN, "Un palacio protonazarí en la Murcia del siglo XIII: al-Qaşr al-Şagīr", Casas y palacios de Al-Andalus, Madrid-Barcelona, 1995, pp. 177-205.

16 En el siglo XVIII sólo se conservaba la escalera y un arco, muy bajo y ancho. Probablemente hubo dos más, ya sustituidos por dobles vanos adintelados. Fotografías y la planta del edificio, en V. TRAVER TOMÁS; Palacio arzobispal de Valencia. Memoria referente a su historia y reconstrucción, redactada por..., Valencia, 1946. Una interesante fotografía muestra dos de los arcos posteriores, en lo que actualmente es un patio de luces. Sin embargo, debe advertirse que el arranque perpendicular no corresponde al arco original, sino a un arco escarzano de menor luz que reutilizó parte de las dovelas primitivas, eliminando el soporte del siglo XIII.

17 El edificio pudo levantarse hacia 1326, cuando se vendió la propiedad al Monasterio de la Valldigna. Para una descripción más detallada A. ZARAGOZÁ CATALÁN y F. IBORRA BERNAD, "Una aproximación a arquitecturas desaparecidas: el palacio episcopal, el palacio de En Bou y la capilla del Real Viejo de Valencia", A. ZARAGOZÁ (ed.), Jaime I (1208-2008) Arquitectura año cero, Valencia, 2008, pp. $134-156$. Nuevas aportaciones y noticias históricas sobre el lugar de Sinyent, I. MATOSES ORTELLS, "Desvelando el arcano de la ribera del Júcar. La casa de Sinyent", Actas del IX Congreso Internacional de Arquitectura en Tierra. Tradición e innovación (en prensa).

18 Véase: F. IBORRA BERNAD, op. cit., (en prensa). Los volúmenes emergentes de las alhanías recayentes al patio y el paralelo con la Almudaina apoyan esta hipótesis. Sin embargo, las torrecillas que flanqueaban el pórtico, según los planos de 1802, no tenían continuidad en el piso principal. Esto hace pensar en una edificación coetánea a los nuevos volúmenes añadidos conformando el patio principal, aunque también 


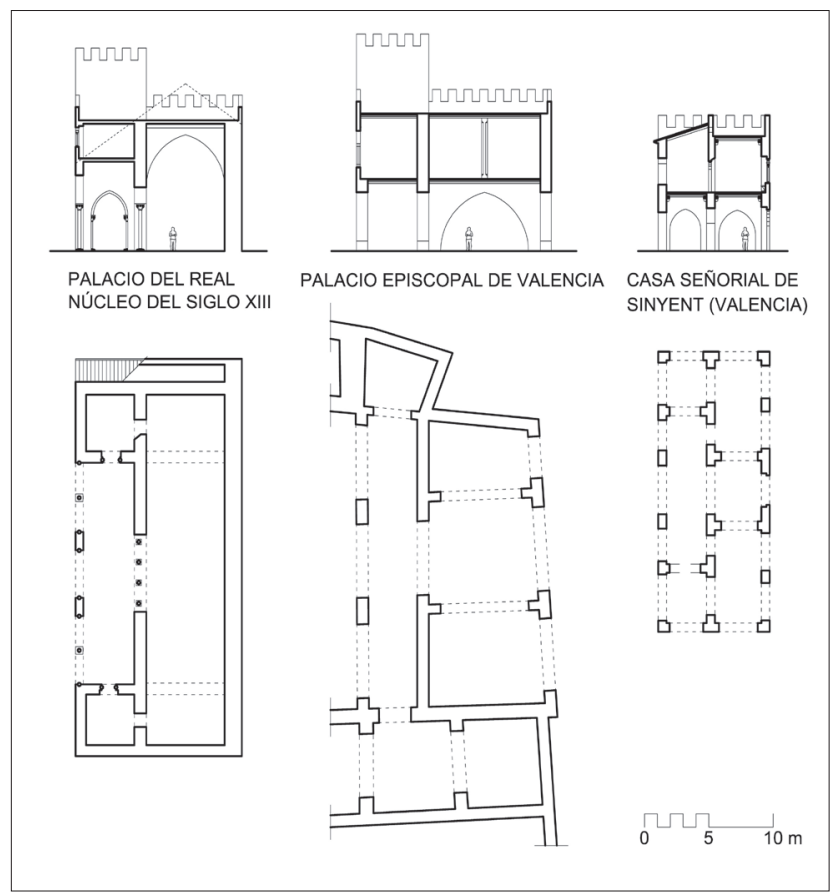

Fig. 1. Restitución de la planta baja y sección del núcleo original del Palacio del Real, del palacio episcopal de Valencia y de la casa señorial de Sinyent.

actuación parecida, pero de nueva planta, se llevó a cabo en el ala primitiva del Palacio Ducal de Gandía, seguramente hacia 1300. En su parte inferior desaparece el pórtico o, más bien, se transforma en escalera, usándose el resto del espacio como un gran salón diáfano. El piso superior se modificó posteriormente, pero las antiguas fotografías muestran todavía la impronta de los volúmenes emergentes de las alhanías, a modo de torrecillas almenadas, flanqueando la llamada Sala de las Coronas. Esta última, de 9 metros de luz, podría haber tenido inicialmente columnas intermedias, o también dos crujías, algo quizás más coherente con el descubrimiento documentado de los restos de una antigua galería cegada que se abría al río. Su configuración no diferiría mucho de la planta alta del Real, tal como se ha propuesto ${ }^{19}$.

puede interpretarse una demolición intencionada para ensanchar una galería ya existente hasta abarcar todo el espacio entre las grandes torres de la ampliación. A la nueva galería pertenecería un extraño capitel de principios del siglo XIV que se halló en las excavaciones de la zona.

19 Esta arcada fue descubierta y documentada cuando los jesuitas compraron el edificio (F. CERVÓS y J.M. SOLÁ, El Palacio Ducal de Gandía [1904], Gandía, 2004, p. 79). Existen también dobles arcos en la parte baja de la Sala de la Cinta, que refuerzan la idea de la doble crujía. Respecto a la cronología, se sabe documentalmente que hacia 1300 se hicieron reformas y se tapiaron unos arcos, aunque es difícil establecer si la estructura que describimos era anterior o posterior a la noticia. (I. AGUILAR y F. MUT, "Palacio Ducal de Gandía", Catálogo de Monumentos y de Conjuntos de la Comunidad Valenciana, Valencia, 1983, tomo I, pp. 448-454). 


\section{Arcos diafragma y salas columnarias}

El término palau, o palacio, se relacionó durante la Edad Media con los grandes salones representativos cubiertos con una estructura de arcos diafragma. La misma palabra se emplearía también de manera genérica para referirse al edificio donde residía el rey o el obispo, caracterizado por tener una gran estancia de este tipo.

El uso de los arcos diafragma para la construcción de iglesias y edificios civiles ha sido ampliamente tratado por Arturo Zaragozá Catalán, completando las aportaciones pioneras de Leopoldo Torres Balbás. Todo apunta a un posible origen romano y su desarrollo en Siria, aunque no parece quedar muy claro cuál sería la vía de entrada en la España medieval ${ }^{20}$. Hay que resaltar, sin embargo, que los ejemplos más antiguos, como la sala baja de Santa María de la Huerta en Soria, la Sala Capitular de Sigena o el dormitorio de Poblet se encuadran en la órbita del gótico cisterciense y se remontan a finales del siglo XII, tras la pérdida de Tierra Santa. En ámbito valenciano el sistema tendrá una buena aceptación en los dos siglos sucesivos para la construcción de los nuevos templos parroquiales, desarrollándose también varias tipologías de palacios y viviendas con espacios diáfanos de grandes dimensiones, siempre en planta baja y con cubierta plana. Finalmente, aparecerá empleado en edificios "industriales", como almacenes, atarazanas y hornos medievales ${ }^{21}$.

Un interesante modelo de vivienda, que tuvo cierto éxito en el área del norte de Valencia y Castellón, consiste en un palau de doble altura al que se adosa lateralmente una crujía de tamaño doméstico en dos plantas. Este esquema recuerda vagamente algunas viviendas populares de Rodas y Creta, estudiadas por Arturo Zaragozá, donde las camas de la familia se disponen adosadas a los muros y flanqueando el espacio central común, liberado con ayuda de algún arco diafragma. El tipo que nos ocupa, sin embargo, segrega físicamente los dos ámbitos y tiene más profundidad. Dos ejemplares de este tipo se conservan fosilizados en la planta baja del castillo de Albalat dels Tarongers, estudiado por nuestra colega María Mestre Antoni ${ }^{22}$. También podemos interpretar una configuración inicial similar en la Alquería Fonda de Campanar, próxima a Valencia, construida en el siglo XIII pero remodelada interiormente en el XIV para obtener dos plantas (fig. 2) ${ }^{23}$. La tipología ha permanecido viva en

20 A. ZARAGOZÁ CATALÁN, Arquitectura gótica valenciana, Valencia, 2000, pp. 23-42. El mismo tema es retomado y ampliado en E. MIRA y A. ZARAGOZÁ (coords.), Una arquitectura gótica mediterránea, Valencia, 2003, vol. I, pp. 110-128.

21 El tema de los hornos es tratado por A. ZARAGOZÁ CATALÁN, op. cit., 2000, p. 25. Respecto a Sagunto, se remite al libro de Francisco Muñoz Antonino.

22 Todo el cuerpo basamental del palacio está formado por dos palaus de gran tamaño, actualmente divididos en dos plantas, junto a los que se conservan las crujías auxiliares muy transformadas.

23 Aparte de la planimetría publicada por Miguel del Rey, conocemos el edificio gracias a la gentileza de su actual propietario, el arquitecto Manuel de Leyva, quien nos informó de las cronologías derivadas del estudio arqueológico realizado por Concha Camps. En éste quedaba patente que los muros se remontaban al siglo XIII y que la estructura basilical actualmente visible, con arcos apuntados, era del XIV. La presencia de un arco original cegado a causa de la obra del XIV confirma estas observaciones. Lo más raro del edificio primitivo es que en lugar de una única puerta se construyeron dos arcos gemelos centrados en la fachada. A falta de una explicación mejor, puede pensarse que se dejó preparado en previsión de una futura división horizontal de la propiedad, quizá entre dos hermanos. 
la tradición popular, aunque sustituyendo los arcos por jácenas y añadiendo un piso superior. Un buen ejemplo es el palacio del Marqués de Benicarló, construido en el siglo XVIII sobre los restos de la residencia del antiguo comendador de Montesa ${ }^{24}$.

Es interesante observar que estos edificios, con su espacio a doble altura soportado por arcos diafragma y la crujía lateral de dos plantas, no se alejan tanto de la sección que podemos restituir en los núcleos primitivos del Palacio del Real, cuyo origen situábamos a mediados del siglo XIII. La principal diferencia sería la posición e importancia del acceso, resuelto en estos últimos a través de un pórtico monumental, y no por el testero.

Hay que señalar también que el Palacio Real Mayor de Barcelona presentaba una configuración similar antes de la reforma de Pedro el Ceremonioso, con una crujía de doble altura y otra de dos plantas, como demuestran las antiguas ventanas románicas conservadas en los muros primitivos, que Julia Beltrán de Heredia considera del siglo $\mathrm{XII}^{25}$. Se conserva también una planta basamental cubierta por dos grandes bóvedas de medio cañón de 8 metros de luz, y se ha supuesto, con bastante lógica, que el muro central continuaba en los pisos superiores, resueltos con forjados de madera. Sin embargo, la sección así reconstruida resulta extraña y la anchura de la crujía doméstica parece exagerada. Vista la tipología anteriormente descrita, cabría plantearse la posibilidad de una crujía residencial menor, de unos 4 metros, correspondiendo los otros 12 metros a un gran salón, que funcionaría muy bien sostenido por arcos diafragma (fig. 2) ${ }^{26}$. Dejamos de momento abierta a la reflexión esta hipótesis, que quizás podría implicar el retraso hasta finales del XII o principios del XIII de la controvertida cronología del edificio.

En parcelas urbanas anchas, de entre 8 y 10 metros, se desarrolló un tipo de vivienda diferente, de tamaño medio. Lo habitual era definir en su planta baja un espacio diáfano de servicio, con proporciones cercanas al cuadrado, donde dos arcos con un apoyo común soportaban el forjado. En el piso alto estaba siempre la vivienda, con un amplio salón cuadrado, que presentaba dos ventanas a fachada y cuya cubierta de madera descansaba en una columna de piedra central, más o menos esbelta. La sala va generalmente acompañada de dos dependencias menores -seguramente alcobas- en la parte posterior o, cuando la parcela lo permite, en un lateral. Esta misma solución se trasladó a los primeros ayuntamientos medievales de la provincia de Castellón, como

24 Las habitaciones de uso cotidiano se encuentran flanqueando un gran vestíbulo de doble altura, mientras que en el piso superior quedan los salones representativos. No se conservan elementos góticos y es posible que se reedificara totalmente, aunque el esquema de vivienda responde al tipo tradicional. Sobre este edificio, véase: E. ADELL, "La casa del marqués", Cepa i raïls en Benicarló, Benicarló, 1979.

25 J. BELTRÁN DE HEREDIA BERCERO, "De la ciudad tardoantigua a la ciudad medieval: Barcelona en el siglo XII”, M. CASTIÑEIRAS y J. CAMPS (eds.), El románico y el Mediterráneo. Cataluña, Toulouse y Pisa (1120-1180), Barcelona, 2008, pp. 39-45.

26 Tomando la planta publicada por A. Cirici se puede comprobar que los contrafuertes de la fachada principal se adosan íntegramente desde fuera, mientras que los del frente posterior quedan dentro del edificio, entre dos muros, con un pequeño suplemento añadido en el exterior. Este suplemento es aproximadamente una cuarta parte del contrafuerte y, además, es imprescindible para la estabilidad del arco actual, si calculamos el estribo con la llamada "Regla de Blondel". Eliminado el suplemento, tenemos el estribo necesario para un arco equivalente a unos $3 / 4$ del existente. 


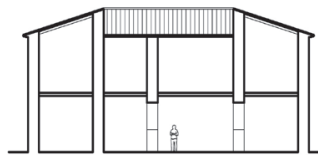

ALQUERIA FONDA (ACTUAL)

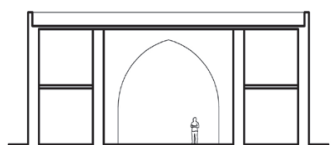

ALQUERIA FONDA (HIPÓTESIS S. XIII)

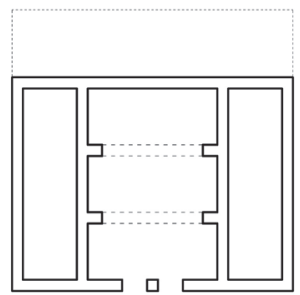

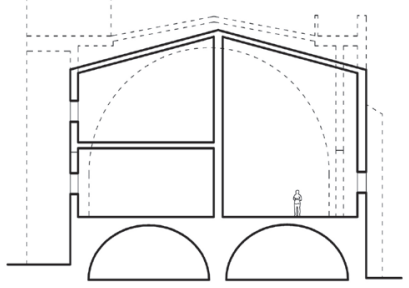

PALACIO REAL MAYOR, BARCELONA (S. XII) HIPÓTESIS DE J. BELTRÁN DE HEREDIA

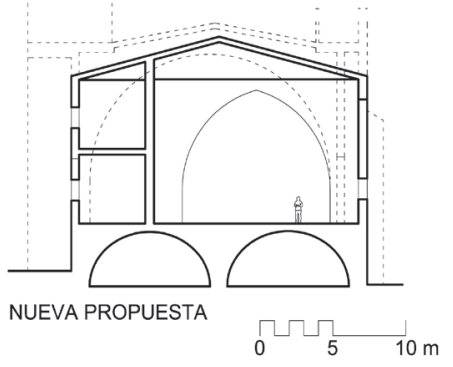

Fig. 2. Alquería Fonda de Campanar (Valencia), sección actual e hipótesis del edificio del siglo XIII. Palacio Real Mayor de Barcelona, hipótesis del edificio del siglo XII (según Julia Beltrán de Heredia) y propuesta con crujías desiguales.

el de Morella (1359-1410) o Catí (1414-1426) ${ }^{27}$. Sin embargo, el origen residencial del tipo queda probado por algunos buenos ejemplos de viviendas del siglo XIV que hubo en Sagunto, como los restos de la Casa del Delme o Diezmo (c. 1350) donde se alojaron obispos y monarcas ${ }^{28}$, o el desaparecido Hostal "La Castellona", antigua casa señorial de los Vives de Cañamás, cuyas pinturas murales del siglo XIV se trasladaron al Museo de Bellas Artes de Valencia (fig. 3) ${ }^{29}$. Todavía anterior sería un edi-

27 F. GRANDE GRANDE, "La Lonja-Casa de la Vila a finales de la Edad Media en las comarcas septentrionales de la Comunidad Valenciana", S. LARA ORTEGA (coord.), La Lonja: un Monumento del II para el III Milenio, Valencia, 1998, pp. 189-204.

28 Para noticias y una reconstrucción del edificio, F. MUÑOZ ANTONINO, op. cit., 1999, pp. 52-64. Aquí nos referimos principalmente al cuerpo izquierdo, levantado en el patio de los antiguos baños árabes, cuyo alfarje -dibujado por Chabret- estaba decorado con motivos andalusíes y escudos que podrían pertenecer al obispo Hugo de Fenollet (1348-1356). Muñoz dibuja en sus plantas grandes arcos que cruzan toda la entrada, indicando que el del patio era escarzano y dibujándolo en la sección transversal del edificio. Al restituir para este artículo la sección longitudinal, hemos advertido que la altura del arranque y el tamaño del estribo hacen imposible pensar en un solo arco, por lo que hemos introducido un apoyo central. Descartamos también la solución de un arco apuntado arrancando del suelo, como en el palacio episcopal de Valencia, porque no hay altura suficiente.

29 F. MUÑOZ ANTONINO, op. cit., 1999, pp. 226-229. Llegamos a esta conclusión a partir de las imágenes de planta baja y descripciones del salón principal publicadas por este autor, contrastando los datos con los planos catastrales actuales (calle Valencia $\mathrm{n}^{\mathrm{o}} 25$ y 27) donde la volumetría general coincide. Teniendo 


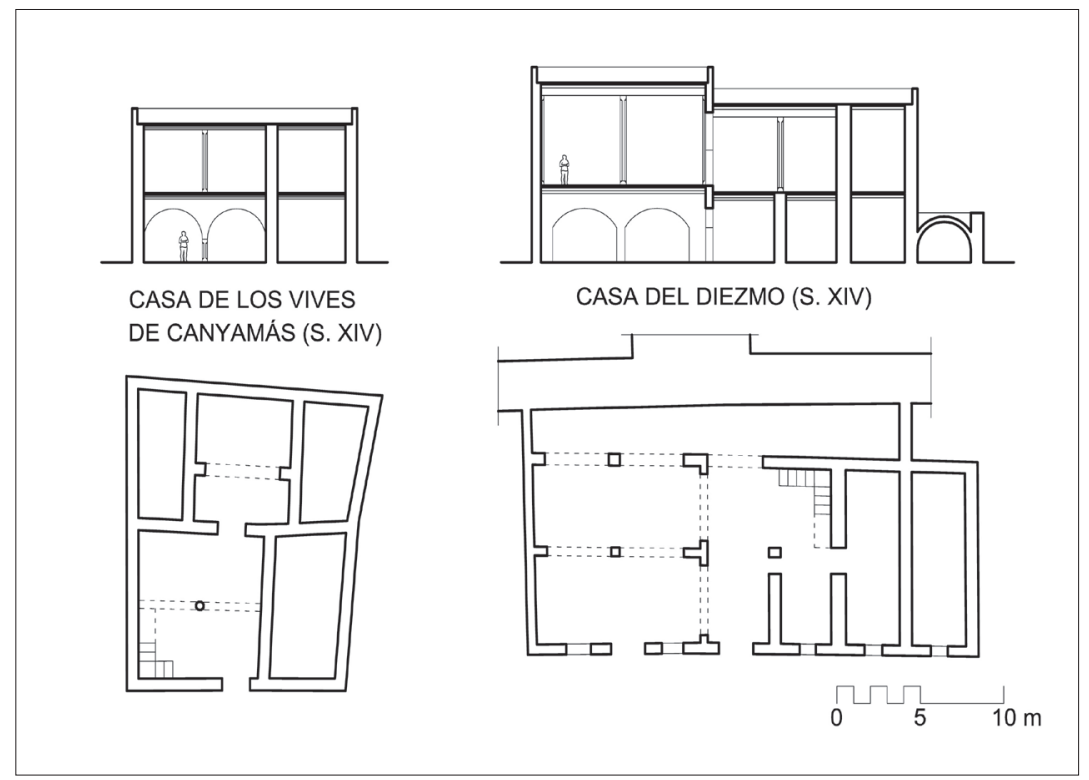

Fig. 3. Restitución de la Casa de los Vives de Cañamás y la Casa del Delme (o Diezmo) en Sagunto.

ficio de Valencia que pudo pertenecer a Arnau de Vilanova $(+1311)$ cuya medianera, con pinturas de tradición románica, se conserva integrada en el Palacio de En Bou ${ }^{30}$.

El origen de estas viviendas podría estar en las casas torre. No está suficientemente estudiada la difusión real que pudo tener esta tipología en ámbito valenciano, aunque puede encontrarse algún ejemplo muy transformado, como la Torre de Cálig, al norte de la provincia de Castellón, donde hay indicios de la existencia de un soporte central. Un prototipo ideal de estas casas torre estaría representado por el enigmático Palacio de los Duques de Santo Stefano en Taormina (Sicilia), levantado en el siglo XIV, aunque algunos estudiosos remontan su origen al XIII ${ }^{31}$. La construcción presenta tres plantas, con cuatro bóvedas en la inferior y dos forjados de madera soportados por columnas centrales en las superiores. Aparte de las ventanas pareadas, evitando el eje de la columna, es interesante observar la presencia de un estrecho balcón ojival centrado, que también existe en el Ayuntamiento de Morella. En ambos

en cuenta que la reconstrucción se hizo en 1945, es casi seguro que se mantiene en pie parte de los muros originales.

30 Véase A. ZARAGOZÁ CATALÁN y F. IBORRA BERNAD, op. cit., 2008, pp. 134-156. La identificación del propietario se basa en la presencia del escudo de los Vilanova aragoneses, así como en la iconografía de los murales, que muestran una enigmática escena vinculada con la alquimia o la medicina.

31 El profesor Marco Nobile, de la Universidad de Palermo, considera que la estructura inicial podría ser de época federiciana. Las ventanas del último piso serían claramente del XIV, pero contrastan con la sobriedad de los huecos inferiores. 
casos podría tratarse del acceso primitivo desde el exterior, anulado por modificaciones posteriores del conjunto.

El ejemplo siciliano nos recuerda también a las torres de dos importantes edificios representados en la vista de Valencia de Anton van der Wijngaerde (1563). Uno de ellos es el palacio de los Berenguer, del cual no tenemos prácticamente ninguna noticia aparte de su imponente presencia a la entrada del viejo camino de Murviedro ${ }^{32}$. Demolido en el siglo XIX, presentaba una volumetría muy parecida a la del Alcázar de Medina de Pomar (Burgos) y probablemente se levantó por las mismas fechas, en la segunda mitad del siglo XIV ${ }^{33}$. El otro edificio es el propio Palacio del Real, ya ampliado con la adición del patio principal y gruesas torres de tres plantas, recrecidas todavía más en época posterior. Desconocemos la configuración interior de las dos torres principales, en la fachada oriental. Sí que sabemos que una de ellas se demolió y reconstruyó como una gran chimenea, mientras que la otra fue siempre la cámara regia y presentaba desde el siglo XIV una gran bóveda de crucería sin soportes. Aunque las ventanas pareadas sugieren la existencia previa de una columna central, cabría pensar también en un espacio áulico singular bajo una armadura ochavada como la que existió en Medina de Pomar, convirtiendo esta cámara real en una auténtica qubba de tradición andalusíi ${ }^{34}$. En el palacio condal de Cocentaina, construido en el siglo XIV a imitación del Real de Valencia, la torre mayor conserva un espacio abovedado en el XVI llamado Sala Dorada. Este sugerente nombre parece hacer referencia a una cubierta de madera de gran riqueza, aunque desconocemos si tendría o no un soporte central.

\section{Plantas en $\mathrm{L}$ y edificios en torno a patio}

En parcelas con cierto desahogo se adosaron la crujía del palau y la residencial a los lados de un patio. El ejemplo más notable es el Palacio del Arcediano en Játiva, fechable en la segunda mitad del siglo XIII, donde se conserva prácticamente íntegro el palau, situado al fondo, aunque nada queda de un ala perpendicular más estrecha, que seguramente tenía dos plantas ${ }^{35}$. Una variante de este tipo la encontramos en las

32 La situación entre el convento de la Zaidía y el Palacio del Real, así como su semejanza a este último, sugieren que pudiera ser el mítico Realet, construido a mediados del XIII como residencia de los hijos de Jaime I y Teresa Gil de Vidaurre. Sin embargo, los torreones del Real se levantaron algo después, como veremos. Además, previamente al sitio de la ciudad en 1363, se había ordenado la demolición de todas las estructuras que por su elevación y fortaleza pudiesen ser usadas por los castellanos en su ataque, excepto el Palacio del Real. Esto incluiría necesariamente el edificio referido.

33 Sobre este último, véase M. SOBRINO GONZÁLEZ, "El alcázar de los Velasco en Medina de Pomar (Burgos). Un espacio áulico andalusí en el Norte de la vieja Castilla”, Loggia, 11 (1996), pp. 10-21.

34 Curiosamente coincide también la dimensión en planta, de 10 metros (9,96 para el caso valenciano). La idea de un espacio tipo qubba, dentro de la Corona de Aragón, aparece a principios del XIV en el castillo de la Zuda de Lérida, y explicaría la tipología adoptada por Alfonso el Magnánimo en el Castelnuovo de Nápoles (A. SERRA DESFILIS, “'È cosa catalana': la Gran Sala de Castel Nuovo en el contexto mediterráneo", Annali di Architettura, 12 (2000), pp. 7-16).

35 Es poco lo que realmente se ha escrito de este edificio. Puede verse: A. SERRA DESFILIS, "Xátiva, la ciudad de los Borja", El hogar de los Borja, Valencia, 2001, pp. 35-47, y más concretamente pp. 42-43. 


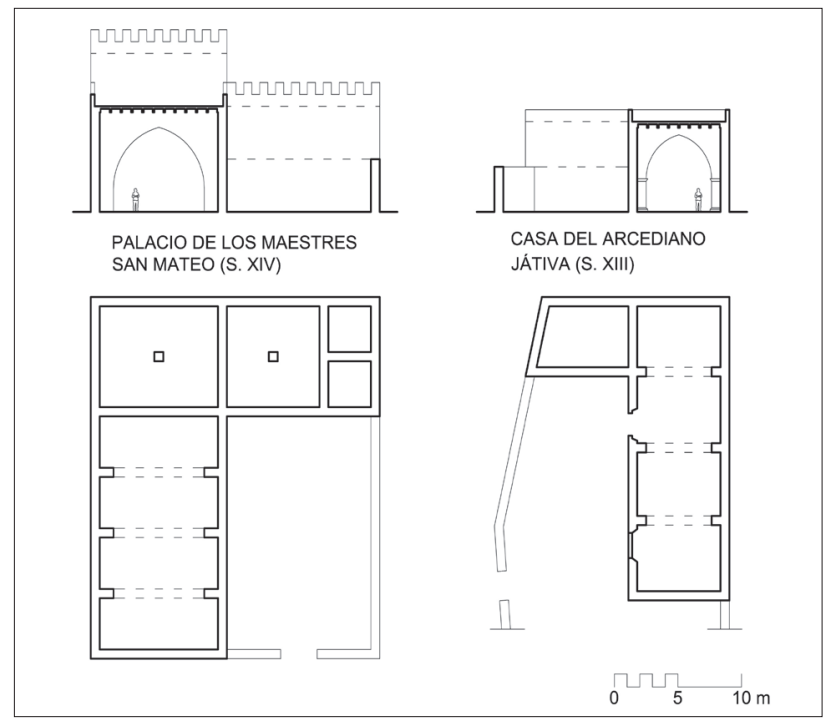

Fig. 4. Restitución hipotética del primitivo palacio de los Maestres de Montesa en San Mateo y palacio del Arcediano en Játiva.

plantas que hacia 1790 hizo Vicente Gascó del desaparecido Palacio de los Maestres de Montesa en San Mateo, edificio documentado desde 1321 aunque probablemente algo anterior (fig. 4) ${ }^{36}$. En ellas es legible lo que parece un gran patio, colmatado en época posterior, así como dos crujías formando una L, en cuyo encuentro se levantaba una torre. Por sus proporciones, podemos considerar que el cuerpo paralelo al acceso era un gran palau con sus arcos cegados posteriormente, mientras que el perpendicular, más corto, correspondería con usos más domésticos y quizá podría tener de origen dos plantas. Similar disposición la encontramos en el castillo de Herbés, muy transformado en el siglo XVII, donde aún son visibles los arcos cegados del antiguo palau, a la izquierda del acceso.

Las plantas en L derivarán hacia los grandes palacios con patio del siglo XIV, donde vuelve a aparecer el palau usado como gran sala de audiencias. Encontramos estructuras de este tipo también en múltiples residencias en Cataluña y Mallorca, como el palacio episcopal de Tortosa, y los palacios reales de Barcelona, Palma y Perpignan, por citar los más conocidos. Salvo la Almudaina de Palma, todos ellos han trasladado ya la sala de arcos diafragma a un primer piso.

El Palacio del Real de Valencia también contaba con un gran palau de 25 metros de longitud y 10 de anchura, que ocupaba toda el ala norte del edificio frente al acceso.

36 A. ZARAGOZÁ CATALÁN, "El palacio de los maestres de Montesa en Sant Mateu”, La luz de las imágenes, Valencia, 1999, tomo I, pp. 116-117. La fundación de la Orden de Montesa se aprobó en 1317 y se confirmó en 1319. En ese momento se escogió la villa más grande y poblada como capital del señorío y debió comenzarse la construcción del palacio (E. GUINOT RODRÍGUEZ, "El Maestrat de Montesa: Els origens d'un territori històric valencià", La Luz de las Imágenes. San Mateo 2005, Valencia, 2005, pp. 55-56). 
La estructura original era un bloque autónomo de doble altura y cubierta plana, similar al que hubo en la Zuda de Lérida, aunque en el siglo XV se levantó un piso superior, quizá rebajando algo la altura del techo para nivelarlo con el resto del conjunto. Una estructura similar debió ocupar toda el ala occidental -actualmente desaparecidadel palacio de los Condes de Cocentaina, levantado en el siglo XIV a imitación del $\mathrm{Real}^{37}$. Ligeramente menor, pero todavía en pie, resulta el palau del Palacio Ducal de Gandía, situado en este caso debajo de las habitaciones principales.

El esquema de patio con palau al fondo sería seguido en residencias urbanas menores, como demuestran las plantas de la Casa Mallent en Sagunto, del siglo XIV y quizá anterior a $1350^{38}$. Pudo haber existido una estructura de este tipo en el Palacio del Almirante de Valencia, cuya parte posterior está actualmente muy transformada. Sin llegar a tratarse propiamente de palaus, podemos rastrear la importancia de salas representativas en planta baja por algunos alfarjes ricamente policromados en las crujías posteriores de los patios de la casa de Joan de Valeriola o del Palacio de Mercader, en la capital valenciana. En la misma línea podría quizá leerse la presencia de techumbres con decoración geométrica en una estancia lateral del piso bajo del palacio de Catalá de Valeriola. No obstante, durante el siglo XV irán ganando protagonismo los salones superiores y las estancias bajas se convertirán poco a poco en espacios de servicio.

Concluiremos comentando brevemente el resto de la organización funcional del Real y sus similitudes con algunas residencias aristocráticas menores. El salón del trono debía ocupar la planta noble del ala sur, directamente comunicado con la cámara del rey que se ubicaba en la torre sudeste, denominada posteriormente Torre de los Ángeles por la decoración de su bóveda. El ala oriental, entre esta torre y otra desaparecida en el siglo XVI, contenía el núcleo primitivo que hemos analizado anteriormente, cuyos espacios estarían reservados al uso más privado del monarca. Quizás la torre septentrional fuera usada por la reina hasta que se edificó el patio anexo a poniente, donde la soberana contaría ya con una sala, cámara y recámara para uso privado. Al oeste del patio mayor existía un gran salón que servía como vestíbulo del que contenía el trono. Allí desembarcaba la escalera -al menos la de finales del $\mathrm{XIV}^{39}$ - y fue usado en ocasiones como comedor. Es posible que en origen estuviera abierto al patio con una arcada, que lo convertiría en una tribuna o vestíbulo exterior, como las que se conservan en Perpignan, el palacio episcopal de Tortosa o el Palacio de la Generalidad de Barcelona.

37 La anchura del ala desaparecida era de unos 10 metros. Su presencia se puede contrastar en las plantas, aunque también es perfectamente visible en el lugar. Debía encajarse en el ala perpendicular, donde parte del muro tuvo que reconstruirse de manera diferente y con una alineación ligeramente inclinada, para buscar la esquina de la torre desde el ángulo del patio.

38 F. MUÑOZ ANTONINO, op. cit., 1999, pp. 112-115. La tradición relata que en esta casa pasó unos días Constanza Miquel antes del nacimiento del futuro San Vicente Ferrer. Aunque el edificio está muy transformado, el tipo de arcos responde a las formas en uso en la primera mitad del XIV.

39 Tipológicamente hay indicios para pensar que antes hubo una primera escalera adosada a la crujía de fachada, como es habitual en muchas residencias aristocráticas valencianas. Esto explicaría la posición desplazada del acceso principal. Además, en los planos de 1802 puede identificarse un paso elevado en el ángulo sudeste, con dos huecos que podrían corresponder a las antiguas puertas. 
Entre los palacios urbanos valencianos es también común que la sala principal se encuentre sobre la crujía de acceso y junto a ella esté el dormitorio -la cambra de paraments o cambra major- seguido por dos o tres recámaras de uso privado, que abarcan un lateral del patio. En la crujía de enfrente suele aparecer otra habitación grande, a la que también se puede acceder desde el desembarco de la escalera, paralela a fachada, por una puerta independiente a la de la sala. Esta habitación grande suele corresponderse con el comedor, aunque alguna vez es usada como estudio, trasladándose el comedor al ala que cierra el fondo del patio.

\section{Escaleras exteriores e influencias italianas}

El principal avance en la arquitectura áulica será la aparición, a finales del XIII o principios del XIV, de los patios con escalera abierta en los territorios ribereños de la Corona de Aragón. Su origen no es autóctono, sino que debería vincularse a la arquitectura desarrollada en el sur de Italia en tiempos del emperador Federico II. El enlace matrimonial del príncipe heredero Pedro de Aragón con Constanza, hija del rey Manfredo -y, por tanto, nieta de Federico- fue el comienzo de una provechosa relación con uno de los núcleos culturales más importantes del Mediterráneo. La invasión angevina supuso el final de la dinastía de los Hohenstaufen y la huida a Aragón de muchos cortesanos afines a su causa, que promoverían unos años después la revuelta de las Vísperas Sicilianas (1282) y la entronización en la isla de Pedro III el Grande.

Los primeros patios con escaleras exteriores aparecen en las residencias de $\mathrm{Fe}$ derico II en Apulia, concretamente en los castillos de Bari, Trani y Gioia del Colle. Todos ellos fueron levantados en época normanda pero restaurados en la primera mitad del siglo XIII ${ }^{40}$. No obstante, las escaleras exteriores tienen una más que probable ascendencia oriental, con precedentes al menos desde el siglo IX (Nilómetro de Rodas y Ribat de Susa, por citar dos bastante conocidos ${ }^{41}$ ) y secuelas cristianas en Rodas, Chipre o Acre ${ }^{42}$. Podemos suponer su llegada a Occidente como fruto de la relación de Federico II con los sultanes de Egipto a raíz de la VI Cruzada, aunque resulta extraña la localización tan específica de estos primeros ejemplos. De hecho, puede comprobarse cómo para el resto de grandes residencias federicianas coetáneas se prefieren los caracoles internos ${ }^{43}$. Ello nos lleva a plantear una posible influencia de los exiliados que habían apoyado el fracasado intento de Federico II para dominar Chipre, y que se establecieron en la Apulia en 1232. Camille Enlart planteó esta vía para explicar la introducción en Italia del gótico francés, muy desarrollado previa-

40 S. MOLA, Itinerario federiciano un Puglia, Bari, 1994, pp. 148-153.

41 Para imágenes de estos edificios y sus escaleras: H. STIERLIN, El Islam, desde Bagdad hasta Córdoba, Colonia, 2002, pp. 142 y 178.

42 En esta última destaca el patio del palacio de los caballeros hospitalarios, que se levantó durante el segundo reino cruzado, entre 1191 y 1291.

43 En algunos casos se trata de escaleras de tipo Vis de Saint-Gilles, cuya costosa ejecución se justifica dentro de una alusión a la Antigüedad o al imperio bizantino. Véase: A. ZARAGOZÁ CATALÁN, "La escalera de caracol tipo Vis de Saint-Gilles", Lexicon, 4 (2007), pp. 7-14. 
mente la isla, por lo que no es descabellado añadir también alguna particularidad de ascendencia oriental ${ }^{44}$.

Lo paradójico del caso es que estas tres fortalezas, situadas al sur de la Península de Italia, quedaron en poder angevino cuando los reyes de Aragón se entronizaron en la Sicilia insular. Aún así, marcarían una profunda huella en la arquitectura de nuestras tierras, algo que entenderemos mejor con algunos datos sobre la historia de dos de ellas. Gioia del Colle fue la residencia habitual de la amante de Federico II, Bianca Lancia, madre de Manfredo -quien heredó del trono- y de Constanza, futura emperatriz de Nicea. Esta última, tras una vida llena de desventuras, pasó sus últimos años en el palacio real de Valencia ${ }^{45}$. Su hermano Manfredo casó en Trani con Elena de Épiro en 1259 y estableció allí su corte, criándose entre los muros de la fortaleza una hija también llamada Constanza, que posteriormente se convirtió en reina de Aragón como esposa de Pedro III el Grande ${ }^{46}$. Sería este último monarca quien impulsaría una importante renovación del Real de Valencia hacia 1280 y no resulta demasiado descabellado asumir que algunos de los felices recuerdos de infancia de la reina y su tía en Italia pudieran servir para intentar emular en la Corona de Aragón el lujo y la pompa de la refinada corte de los Hohenstaufen sicilianos.

La influencia italiana es patente en la configuración del Palacio de los Reyes de Mallorca en Perpignan, de planta perfectamente regular y con dos escaleras exteriores gemelas. El edificio se levantó en tiempos de Jaime II (1276-1310), hermano de Pedro III y, aunque la zona del acceso parece estar documentada hacia 1285, las noticias de las principales actuaciones remiten a los últimos años del reinado ${ }^{47}$. También podemos encontrar ecos italianos en el Real de Valencia, cuya distribución y programa guarda grandes afinidades con la residencia de Perpignan, aunque resuelto de una manera más torpe y primitiva (fig. 5$)^{48}$.

En el caso valenciano también hay italianismos patentes. Podemos relacionar con Trani el gran palau o sala de arcos diafragma al fondo del patio y quizá la configuración del frente oriental con sus dos grandes torres. Respecto a Gioia del Colle, comparten la posición desplazada del acceso, pegado a la torre para poder situar una escalera sobre la misma, accediendo directamente al salón del Trono, que en ambos casos queda en el cuerpo de fachada. La ubicación de la escalera en el Real varía, pero la posición de algunos huecos y sobre todo el arraigo de esta configuración en muchas residencias urbanas medievales (Almirante, Valeriola, Mosén Sorell, etc.) hacen pensar que, si no se ejecutó, al menos se llegó a plantear. Podrían buscarse más

44 C. ENLART, Gothic Art and the Renaissance in Cyprus [1913], Londres, 1987, p. 22.

45 M. ORDEIG CORSINI, Constanza Hohenstaufen, Emperatriz de Grecia, Valencia, 2001.

46 En esta fortaleza fue donde los angevinos capturaron a Elena de Épiro en 1266, tras la derrota de Manfredo en la batalla de Benevento. Posteriormente tuvieron lugar allí los esponsales entre Carlos de Anjou y Margarita de Nevers (1268) y los del príncipe Felipe con Ithamar Comnena (1271). S. MOLA, op. cit., 1994, pp. 148-153.

47 Sobre la organización de las estancias de los palacios de Jaime II en Palma y Perpignan, G. KERSCHER, "Herrschaftsform und Raumordnung", C. FREIGANG, La arquitectura gótica en España, Frankfurt-Madrid, 1999, pp. 251-272.

48 Esto es visible sobre todo en la articulación del ala oriental con el resto y la adición del patio de la Reina, que en Perpignan está totalmente integrado. 


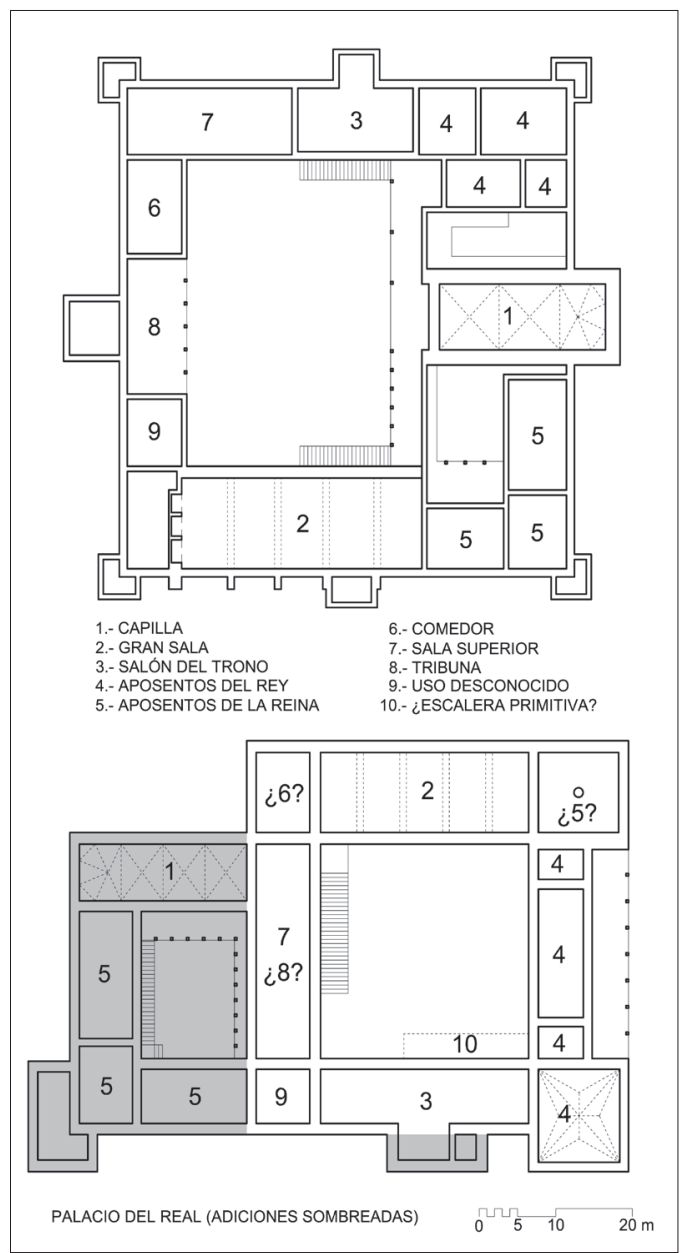

Fig. 5. Planta noble del Palacio de los Reyes de Mallorca en Perpignan y restitución del Real de Valencia en el siglo XIV, evidenciando los añadidos sobre el proyecto original.

semejanzas, pero los dos edificios italianos han sufrido graves transformaciones y mutilaciones, mientras que del valenciano sólo conservamos los planos.

La documentación de obras en el Real remite principalmente a actuaciones a lo largo del siglo XIV, lo que ha llevado tradicionalmente a pensar en una construcción tardía. Sin embargo, las analogías con Perpignan deberían hacernos reconsiderar la cronología. Varias noticias se remontan a principios del XIV, e incluso se puede rastrear una actividad constructiva importante entre 1280 y $1285^{49}$, coincidiendo con el

49 M. GÓMEZ-FERRER LOZANO, op. cit., 2012, p. 26. Durante el sitio de Balaguer (26-6-1280) en el que el rey ordena a los sarracenos neófitos del Reino, al norte del Xúquer, que acudan a trabajar en las obras del Real en el número que requiera Vives b. Vives, judío supervisor de las mismas (Archivo de la Corona de 
breve reinado de Pedro el Grande (1276-1285). La invasión francesa, la prematura muerte del monarca y las guerras de Sicilia y Mallorca podrían haber estancado las obras durante dos décadas, culminándose en tiempos de Jaime II (1291-1327).

Hay varias razones para pensar que la ampliación italianizante del Real estaba ya proyectada en 1280. Es en esta época cuando la reina Constanza y su tía, la emperatriz, tendrían una máxima influencia en la propuesta y, por otra parte, cualquier diseño posterior a revuelta de las Vísperas (1282) habría mostrado una mayor influencia de la arquitectura siciliana insular, puesto que el monarca conocería de primera mano residencias tan suntuosas y sorprendentes como el Palacio Real de Palermo, con sus torres linterna y mosaicos, o el enigmático Castel Maniace de Siracusa, con su grandioso salón de recepciones hipóstilo. No obstante, el Real se concluyó varias décadas después y es seguro que se incorporaron novedades, como el evidente añadido del patio de la reina y quizá las dos grandes torres orientales ${ }^{50}$.

\footnotetext{
Aragón, CR reg 48, fol 67r). Ya en Valencia (20-10-1280) Pere I, rey de Valencia, ordena a Pere de Libià que entregue a Vives, hijo de Yosef b. Vives, los 8.000 sueldos que ha de recibir de los judíos de Valencia para que sean invertidos en la construcción del Real. El profesor Serra hace referencia a que las obras en esta época se deben a la estancia de su esposa Constanza (L. ARCINIEGA GARCÍA y A. SERRA DESFILIS, "Cort e palau de rey. El palacio real en época medieval", J.V. BOIRA MAIQUES (coord.), El Palacio Real de Valencia. Los planos de Manuel Cavallero (1802), Valencia, 2006, p. 83).

50 El posible origen de estas torres sería el Alcázar Menor de Murcia. Fue Jaime I quien sofocó la revuelta de los moriscos murcianos en 1266, en apoyo de su yerno Alfonso X de Castilla, y visitó nuevamente la ciudad en 1274. Su nieto Jaime II ocupó el reino entre 1296 y 1304, en un intento frustrado de incorporarlo a la corona de Aragón. F. IBORRA BERNAD, op. cit., (en prensa).
} 